aussi indispensable pour débattre des humanités, de l'humanisme et des études de la Renaissance. Compagnons des chercheurs spécialistes, il le sera également pour leurs collègues historiens et historiographes dans la rigoureuse analyse de ce qu'est une période et de sa construction.

HÉLÈNE CAZES

University of Victoria

\title{
Lemon, Rebecca.
}

\section{Addiction and Devotion in Early Modern England.}

Philadelphia: University of Pennsylvania Press, 2018. Pp. xv, 258. ISBN 978-08122-4996-5 (hardcover) US\$65.

The emotional and intellectual dimensions of early modern subjecthood remain topics of continued critical interest in the disciplines of literature, history, and religion, due in part to the ways in which those dimensions have been illuminated strikingly by research undertaken since the turn of the century. Work especially on the passions by such scholars as Christopher Tilmouth, Freya Sierhuis, Brian Cummings, and Russ Leo offers badly needed new perspectives on the questions both of how early modern subjects felt, and of how they might have thought about what they felt. Yet the particular character of the experience of feeling or thinking remains elusive as an object of scholarly apprehension. Rebecca Lemon's Addiction and Devotion in Early Modern England seeks to trace the outlines of one aspect of this experience by examining the conceptual status of addiction in the late sixteenth and early seventeenth centuries, and the implications of this status for different forms of deep intellectual or emotional commitment. Addiction as a term was applied, Lemon argues, to a much wider range of behaviours than is typically the case in contemporary culture; in addition, the ethical valence of the behaviours described by addiction was much more varied. Early modern addictions could be ethically admirable (to study or to God) or undesirable (to drink). As such, the book suggests, the study of addiction can offer a novel approach to early modern interiority because it is legible as a species of devotion.

At what point, then, does commitment become addiction? Is it an act of the will? And how is addictive behaviour perceived? In a suite of chapters at the 
heart of the book, Lemon examines love, friendship, and drink in Shakespeare in order to demonstrate that although the will and addiction may be related, the most addictive behaviour is constituted by an effective dissolution of the will into the object of an individual's addiction. For instance, in Twelfth Night, Sir Toby's and Sir Andrew's drunkenness is not, Lemon argues, intelligible as addiction because it represents an interminable telescoping of the self. Olivia's, Viola/Cesario's, and Orsino's devotion to love is, however, more clearly addictive because the love that emerges in each character serves to replace individual desire with a form of compulsive devotion to the beloved. This is not to say that alcohol cannot serve as a site of addiction. In the Henry IV plays, Falstaff's drunkenness derives not from an insatiable and self-indulgent appetite but from his continuing attempts to devote himself to Hal. Drink is, as Lemon notes, "the material condition of their friendship" (80). However, as Falstaff becomes increasingly alienated from Hal, drunkenness comes to represent for him the endlessly deferred moment of commitment. As a result, his subjection to alcohol takes the place of the subjection that he originally desired, and the twin presentation of addiction as disease and as devotion in his character is in part why audiences tend to respond sympathetically to Falstaff. Similarly, Othello's surprisingly sympathetic treatment of Cassio's drunkenness (surprising because drunkenness would within early modern legal systems generally exacerbate rather than mitigate his culpability in the brawl in act 2) reflects a consideration of Othello's predicament as well. Addicted alternately to friendship and to love, Othello's crimes can be seen, like Cassio's, as resulting in part from an absence of volitional agency in the face of addiction.

The notably excellent chapter on health drinking deserves particular mention here. While it is not as well-integrated as the first four substantive chapters, all of which concern themselves specifically with individual plays, the mini-cultural history it presents conveys just as successfully the conceptual capaciousness of addiction and the ways in which the ethical valence of addiction is subject to change in early modern culture. In radical Protestant tracts of the 1580s, the practice of health drinking is generally condemned just as it is, Lemon shows fascinatingly, on the contemporary public stage. Yet during the extended political and military conflicts between parliament and the king beginning in the 1630s, health drinking experienced a surprising renaissance in royalist poetry, where it is framed as a celebration of community. The addictive (as opposed to merely convivial) aspects of health drinking critiqued in earlier 
writing-namely, its inclination to excess and the compulsory nature of the practice-are precisely what royalist poets praise. For these writers, health drinking presents an opportunity to submit oneself wholly to a community construed both congenially and politically.

The book's conceptual contributions to the field, as well as the analytical contributions of its chapters on Shakespeare and health drinking, outweigh dramatically its few inconsistencies. Its chapter on Faustus offers an ingenious reading of the play, but one the book does not substantiate fully. Missing here is a more developed account of the status of the will in Reformed discourses of repentance. Additionally, it would have been helpful for the book to articulate in greater detail its understanding of the conceptual significance of a contemporary (that is, a twenty-first-century) re-evaluation of addiction as a category of behaviour that might, as it did in the early modern period, generate positive as well as negative connotations; both the Introduction and the Epilogue seem to be making this suggestion. If, as Lemon indicates, one important aspect of addiction is that it describes a "shared process of being in relation" (167), is it not the case that contemporary cultures possess adequate resources with which to characterize this process or the resulting forms of relation without turning to the notion of addiction? Perhaps we do not, but the book does not take up this discussion directly. Regardless, as a literary and cultural study, Addiction and Devotion performs valuable scholarly work by recovering a lost history of addiction, and illuminating a wide range of cultural attitudes both towards specific addictive practices and towards different forms of addiction as determined by the relationship of the addict to their object.

DAN BREEN

Ithaca College

\section{Parker, Patricia.}

Shakespearean Intersections: Language, Contexts, Critical Keywords.

Philadelphia: University of Pennsylvania Press, 2018. Pp. $409+12$ ill. ISBN 978-0-8122-4974-3 (hardcover) US $\$ 59.95$.

Patricia Parker's Shakespearean Intersections epitomizes what its author does best: extracting potent lexical essences from the lowest-hanging to the 